تأثثر إستخدام أنشطة الذكاءات المتعددة على مستوى الأداء المهارى لسباحة الصدر لطالبـات الكلية ذوى صعوبات التعلم.

مايسة محمد عفيفى السبد

قسم الرياضات المائية والمنازلات ـ كلية التربية الرياضية بنات - جامعة الزقازيق - جمهورية مصر العربية.

المقدمة ومشكلة البحث

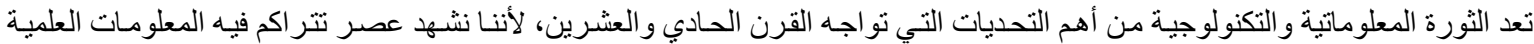

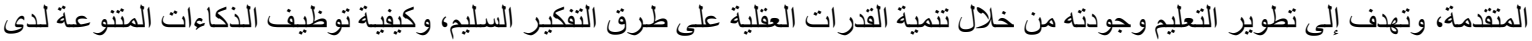

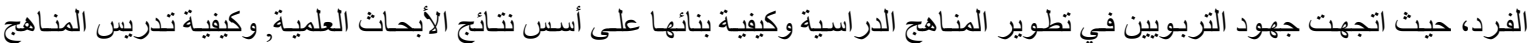

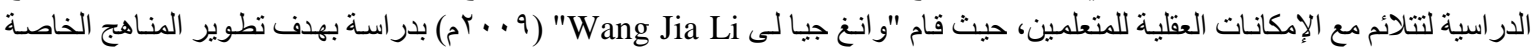

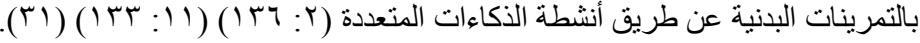

و الصف الدر اسي مكان يظهر فيه التنوع و الاختلاف جلياً بين المتعلمين فهناك متعلمون من كل الأعمار و الأجناس و الثقافات، كما أن فئاتهم

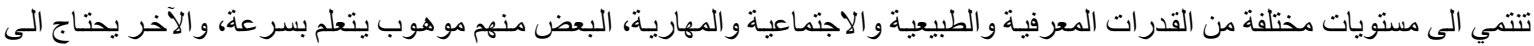

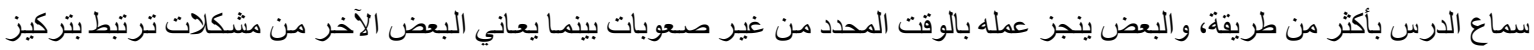

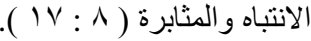

ويظهر أيضاً داخل الصف الدراسى الطلاب ذوى صـوبات التعلم و الذين يتمتعون بذكاء عادي متوسط او فوق المتوسط، وفي الوقت نفسه

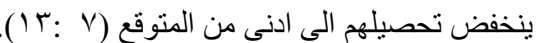

ويو اجه النظام التعليمي في دول العالم جميعها مشكلة صعوبات التعلم، إذ تسهم بدور كبير في ارتفاع نسبة الرسوب بين الطلاب كمـا تعد سبباً

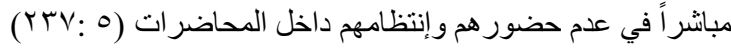

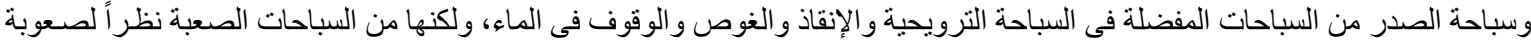

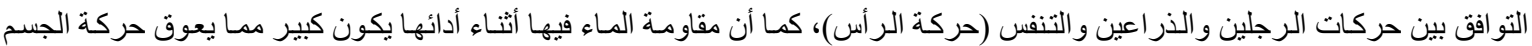

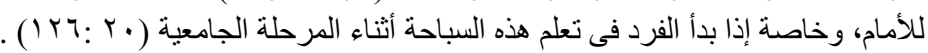

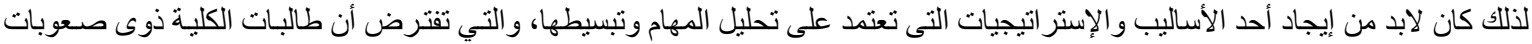

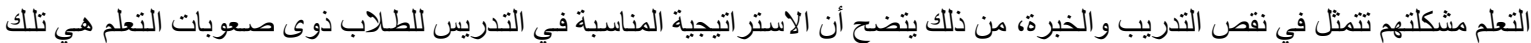

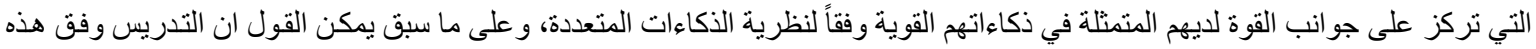

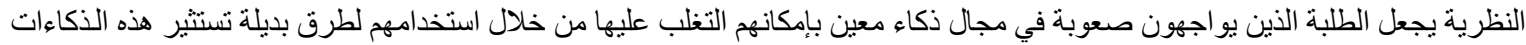

$(110,1 \vee \leqslant: 1 \cdot)$

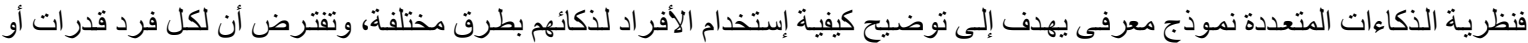

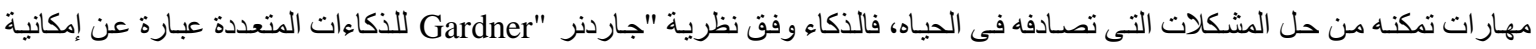

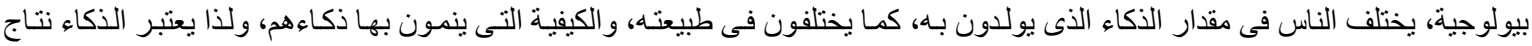

للتفاعل بين العو امل التكوينية و العو امل البيئية (r⿳r).

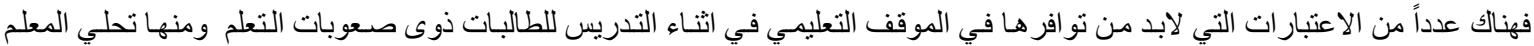

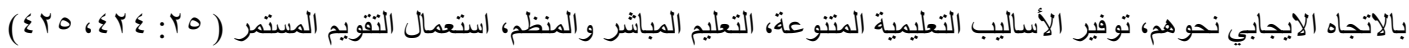

و هذه النظرية من النظريات التى لها دور كبير فى العملية التعليمية والتربوية حيث أنها ركزت على أمور غفلت عنها النها النظريات الأخرى حيث

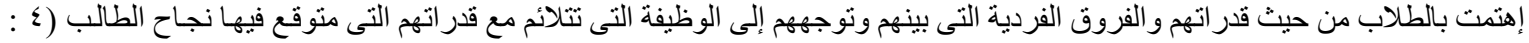

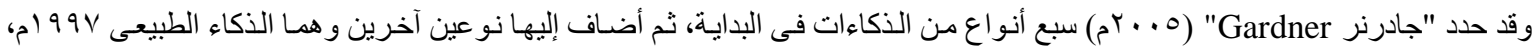

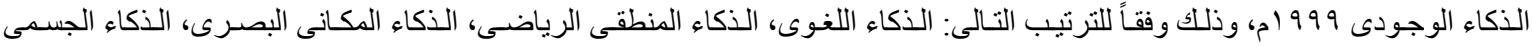

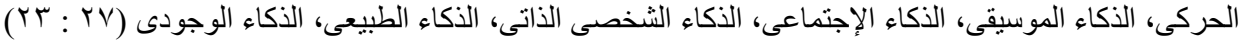


ومما لا شك فية أن أنشطة الذكاءات المتعددة كأسلوب من أساليب التدريس حققت طفرة فى مجال التعليم والتخطيط لتطوير المناهج التعليمية ممـا

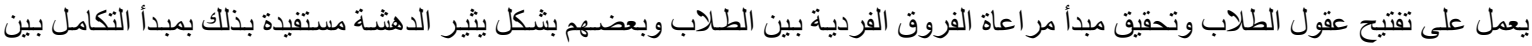

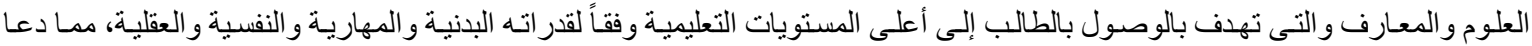

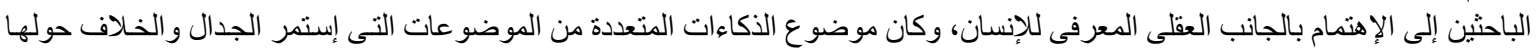

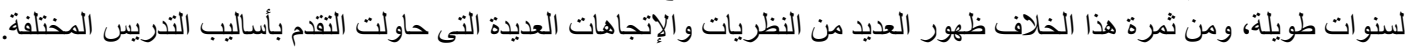
لذا لاحظت الباحثة من خلال عملها مدرس بقسم الرياضات المائية وجود بعض الطالبات ليس لديهن القدرة على التفاعل و التعامل مع الآخرين

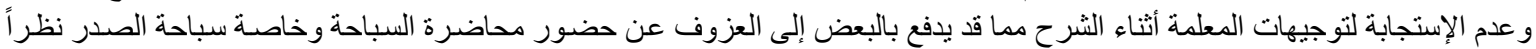

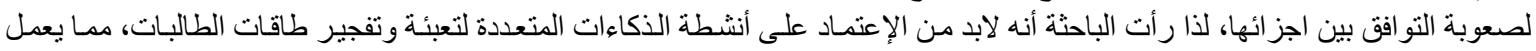

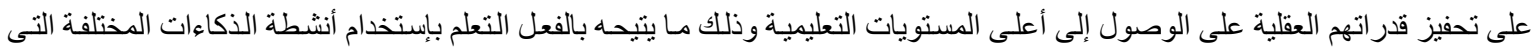
تعمل على تتشيط أشكال النشاط العقلى لاى الطالبة.

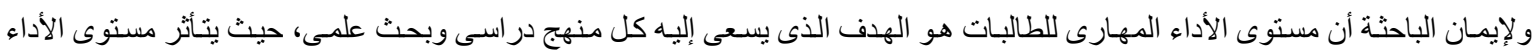

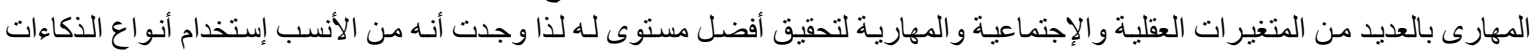

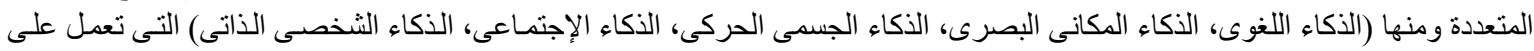

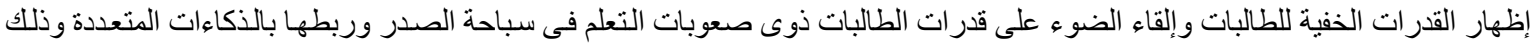
لتفجير طاقتهم للوصول إلى أعلى مستويات الأداء. و على حد علم الباحثة لم تجد أى در اسة فى المجال الرياضى قد تناولت الذكاءات المتعددة مع الطلاب الذين لديهم صعوبات تعلم. هدف البحث : يهدف البحث إلي التعرف على تأثير برنامج تعليمى بإستخدام أنشطة الذكاءات المتعددة على مستوى الأداء المهارى لسباحة الصدر لطالبات الكلية ذوى صعوبات التعلم.

فروض البحث:

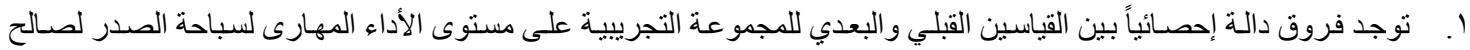
القياس البعدي.

r. توجد فروق غير دالة إحصائياً بين القياسين القبلي و البعدي للمجموعة الضابطة على مستوى الأداء المهارى لسباحة الصدر. r. توجد فروق دالة إحصائياً بين القياسين البعديين لكل من المجمو عتين التجريبية، الضابطة فى مستوى الأداء المهارى لسباحة الصدر للمجموعة التجريبية.

(المصطلحات:

نظرية الذكاعات المتعددة: "نموذج يصف كيف يستخدم الأفر اد ذكاءاتهم المتعددة لحل مشكلة ما، وتركز على العمليات التى يتبعها

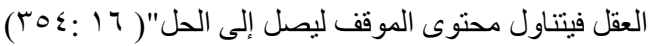

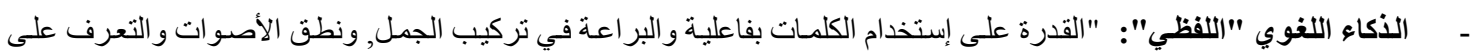

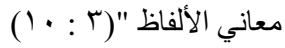

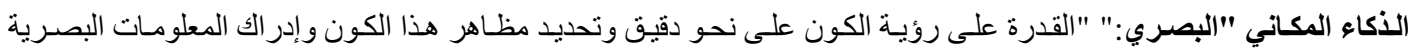

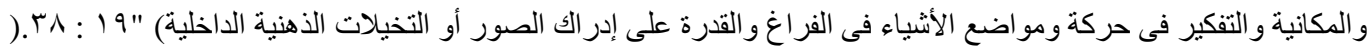

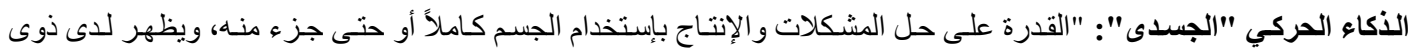

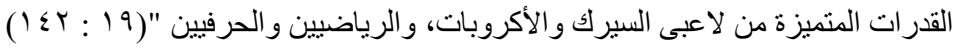

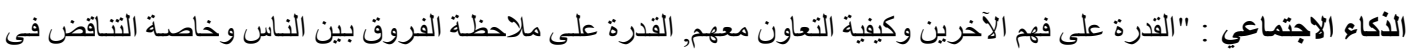

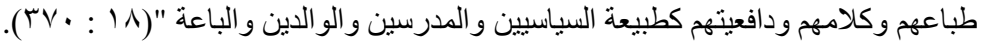
الأكاء الثخصي: "هى قدرة الطالب على فهمه لمشاعره و أفكاره وقيمه الذاتية، والأذكياء فى هذ النمط يظهرون الميل إلى المحافظة

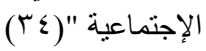




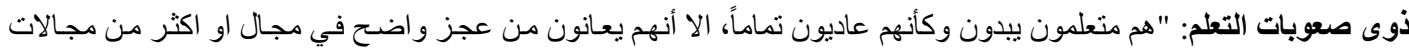

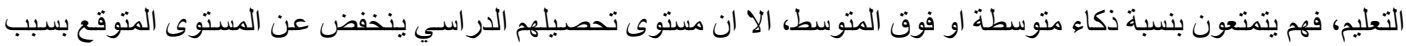

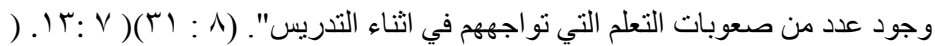

الار اسات المرتبطة: ات

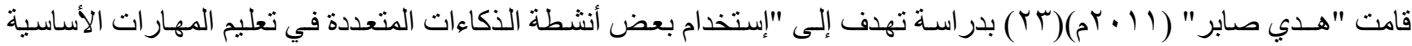

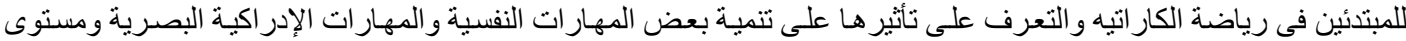

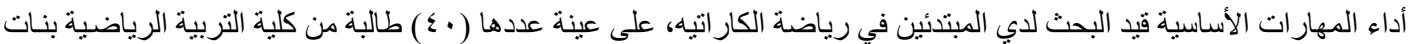

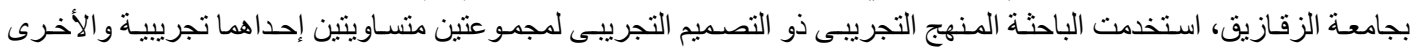

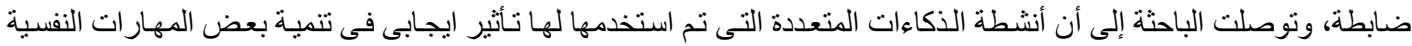
و المهار ات الادر اكية البصرية و على مستوى الأداء المهارى لدى طالبات الكلية أكثر من الطريقة التقليدية.

قام "صبحى الحارثى" (9 + . rم)(9) بدر اسة تهدف إلى إعداد مقياس لصعوبات التعلم الأكاديمية وتصميم برنـامج إرشادى لتحسين

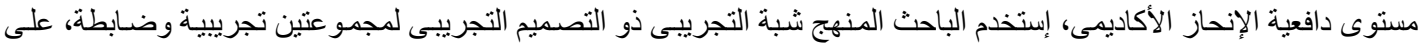

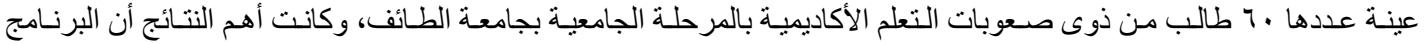

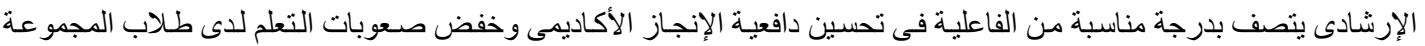

التجريية.

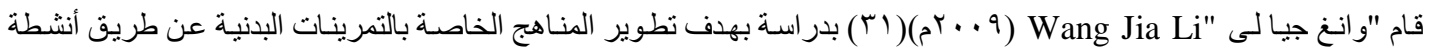

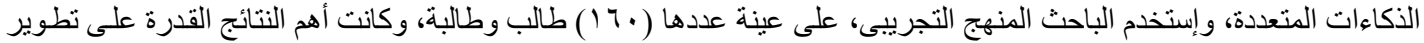

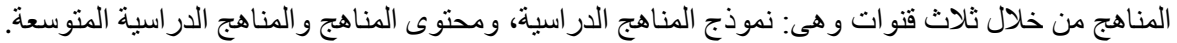

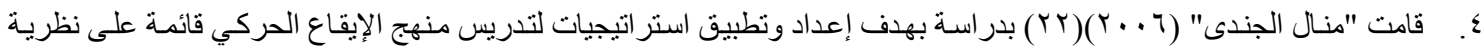

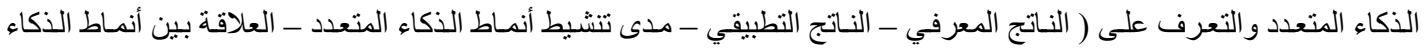

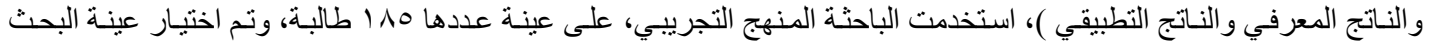

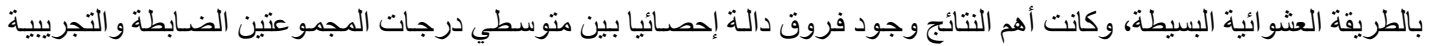

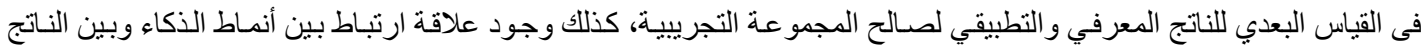

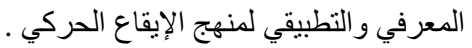

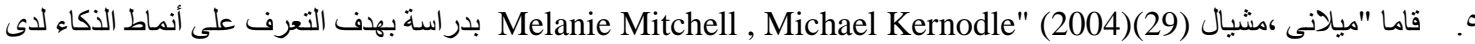

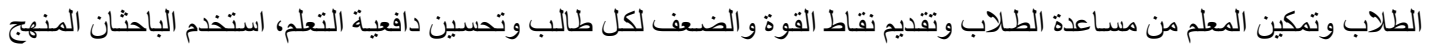

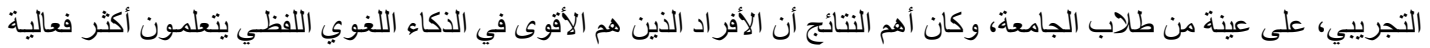

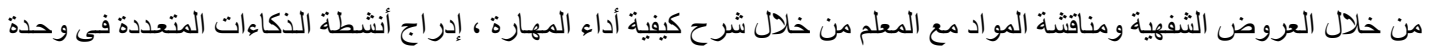

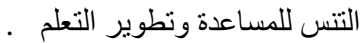

ج. قام "كوف (28)(2003) "Koffs,s " بدراسة بهذف التعرف على علاقة الذكاء وتعليم الرقص، واستخدم الباحث المنهج الوصفي،

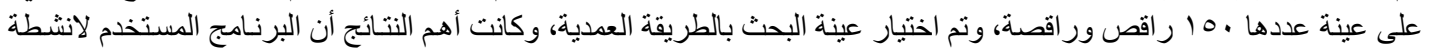

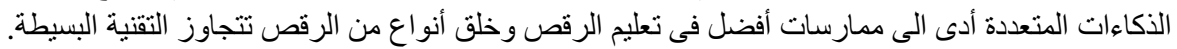

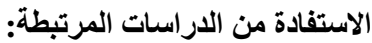

من خلال إطلاع الباحثة على الدراسات المرتبطة تمكنت من تحديد هدف البحث و إختيار المنهج المناسب للار اسة، كما ساعدت هذه الدر اسات الباحثة فى إجر اءات ضبط العينة ووضع الفروض وإختيار أدوات البحث وفترة تطبيق الدراسـة وتحديد الأساليب الإحصائية المناسبة.

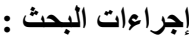

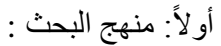

استخدمت الباحثة المنهج التجريبى وذللك لملائمته لطبيعة البحث باستخدام التصميم التجرييى ذو القياس القبلى البعدى لمجمو عتين إحداهما تجريبية والأخرى ضابطة . ثانياً: مجتمع و عينة البحث 


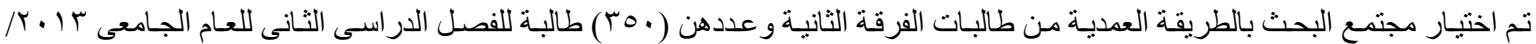

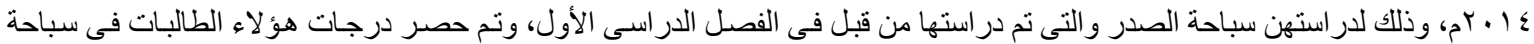

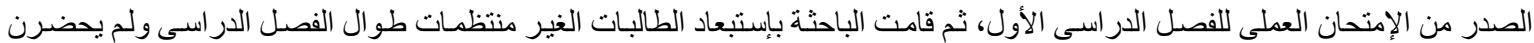

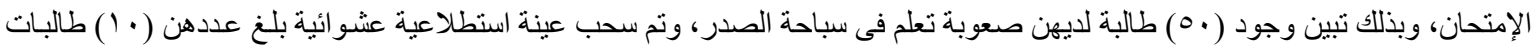

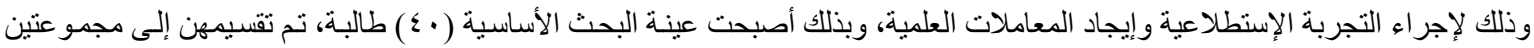

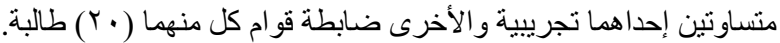

وقامت الباحثة بايجـاد التجانس لمجتمع البحث في (متغيرات النمو، إختبار الذكاء لـر افن، إستمارة البيانات الإجتماعية والإقتصـادية، إختبار

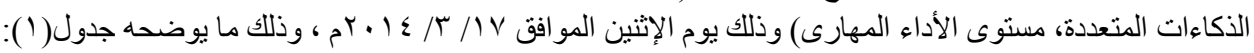

\section{جلول (1)}

توصيف مجتمع البحث

\begin{tabular}{|c|c|c|c|c|c|c|}
\hline معامل الإلتواء & المعيارى الإنحراف & الوسيط & الحسابي & القياس & \multicolumn{2}{|c|}{ المتغيرات } \\
\hline$\because$ Vo & $\varepsilon .79$ & $17 . .$. & 171.11 & سم & 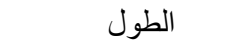 & \multirow{3}{*}{$\frac{1}{3}$} \\
\hline $.07_{-}$ & V.IY & $70 . .$. & 7ז.71 & كجم & 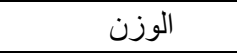 & \\
\hline $1.01-$ & 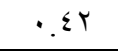 & $19 .$. & $1 \wedge . \vee \wedge$ & سنه & 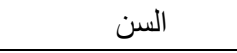 & \\
\hline$\because 9$. & 7.0 & or... & $O \leqslant . A T$ & درجة & \multicolumn{2}{|c|}{ إختبار رافن } \\
\hline$\cdot$.r人 & 1.99 & $1 \varepsilon \ldots$ & $1 \leq .1$ & درجة & \multicolumn{2}{|c|}{ إستمارة البيانات الإجتماعية و الإقتصادية } \\
\hline$\because \vee 9$ & r.01 & A. ro & 1.91 & درجة & الذكاء اللغوي & \multirow{5}{*}{ 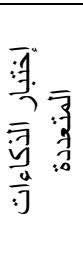 } \\
\hline $.7 \varepsilon$ & 1.19 & 7.0 & $7 . \wedge \wedge$ & درجة & الذكاء البصري & \\
\hline$\cdot r o_{-}$ & $1.71 \leq$ & $0.1 \% 0$ & $\leqslant .99$ & درجة & الذكاء الثخصي & \\
\hline$\cdot r \cdot$ & $1 . \times 9$ & r.o. & $r .71$ & درجة & الذكاء الاجتماعي & \\
\hline$\cdot .7-$ & $1 . V \varepsilon$ & $v_{0} 0$ & V.YTO & درجة & الذكاء الحركي & \\
\hline $.11_{-}$ & . & $\because 0$ & $\because \leqslant \Lambda$ & درجة & وضع الجسم & \multirow{5}{*}{ 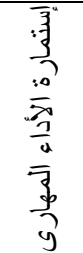 } \\
\hline$\cdot r \varepsilon_{-}$ & $\cdot r v$ & $\because 0$ & $\cdot \leqslant V$ & درجة & حركات الرجلين & \\
\hline$\because 0^{0}$ & $\cdot 4$ & $\because 0$. & $\cdot \leqslant \varepsilon$ & درجة & حركات الذر اعين & \\
\hline$. .01-$ & .47 & .0 & $\cdot \varepsilon r$ & درجة & التنفس & \\
\hline$\because \leqslant 9-$ & $\cdot r V$ & .0 . &..$\leqslant \varepsilon$ & درجة & التو افق الكلى & \\
\hline
\end{tabular}

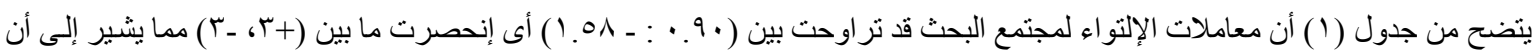
مجتمع البحث يقع تحت المنحنى الإعتدالى. وقد تم تنفيذ خطوات البحث و إجر اءاته وفقاً للخطة الزمنية التى يوضحها الجدول التالى:

جل جلول (r)

الخطة الزمنية لإجراءات البحث

\begin{tabular}{|c|c|c|c|}
\hline \multicolumn{2}{|c|}{ الفترة الزمنية } & \multirow{2}{*}{ الإجراءات البحثية } & \multirow{2}{*}{ b } \\
\hline إلى & من & & \\
\hline $\mathrm{S}^{r \cdot 1} \leqslant / r / 17$ & $\rho^{r \cdot 1} \leq / r / 9$ & الدراسة الإسنطلاعية. & 1 \\
\hline- & 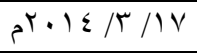 & التجانس & $r$ \\
\hline- & 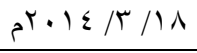 & القياس القبلى (التكافؤ). & $r$ \\
\hline $\mathrm{e}^{r+1} \leq 10 /{ }^{2}$ & $\mathrm{~S}^{r \cdot 1} \leq / \mu / 19$ & تطبيق تجربة البحث الأساسية. & $\varepsilon$ \\
\hline- & $S^{T \cdot 1}=10 / T^{2}$ & القياس البعدى. & 0 \\
\hline
\end{tabular}

ثالثاً: وسائل جمع البيانات 


$$
\begin{aligned}
& \text { - كامير ا فيديو للتصوير. } \\
& \text { جهاز عرض بيانات - جهاز كمبيوتر - فيديو. } \\
& \text { جهاز الرستاميتر لقياس الطول (بالسنتيمتر). } \\
& \text { - ميزان طبى لقياس الوزن (بالكيلو جرام). }
\end{aligned}
$$

وقد تم معايرة بعض الأجهزة بأجهزة اخرى مماتلة للتأكد من سلامتها ودقتها للقياس. ب- أدوات البحث

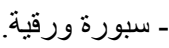

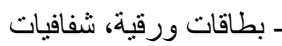

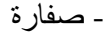

ـ ألوان (خشب - شمع ) للتلوين
- ملوحات طفو

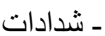

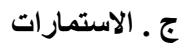

- استمارة استطلاع رأى الخبر اء لتحديد النسبة المئوية لاستخدام أنشطة الذكاءات المتعددة (مرفق؟).

- إستمارة البيانات الإجتماعية و الإقتصادية لدراسة مدى تأثير هذا المتغير على شخصية الطالبات وسلوكهم إعداد الباحثة

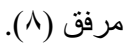

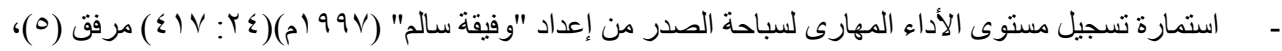

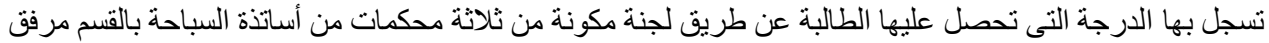

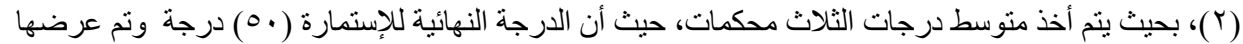

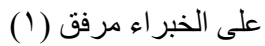

دـ المقاييس

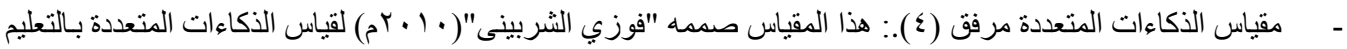

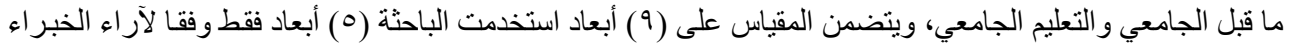

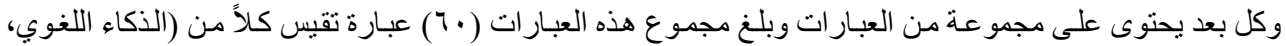

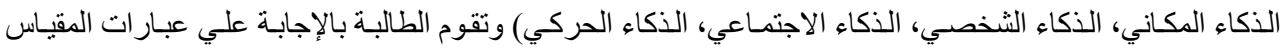

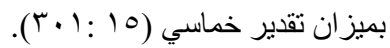

النسبة المئوية لآر اء الخبراء حول أنشطة الذكاءات المتعددة، وجدول (†) يوضح ذلك.

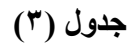

الأهمية النسبية لأنشطة الذكاءات المتعددة

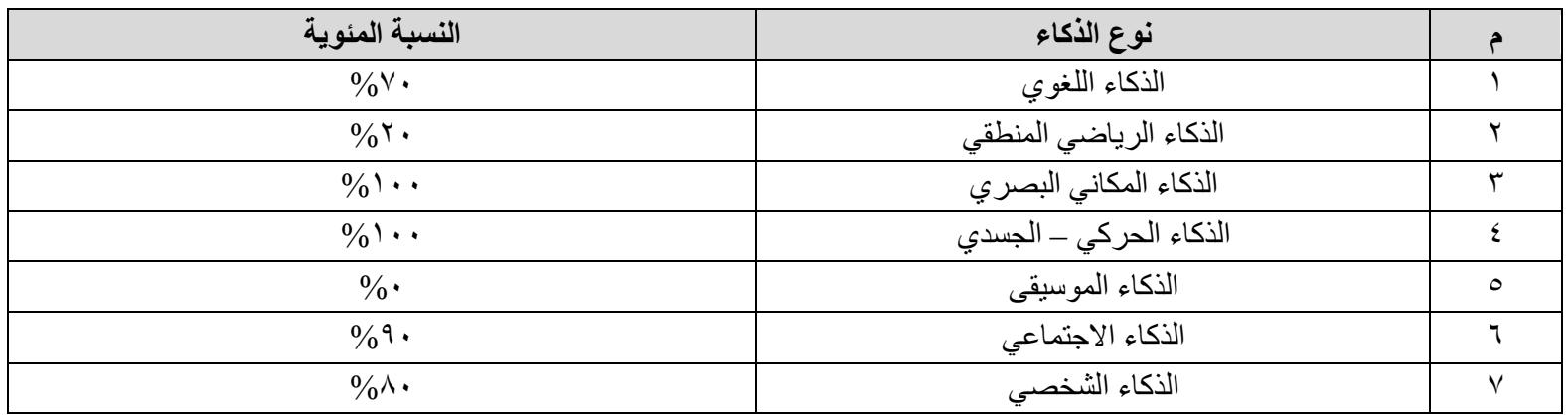

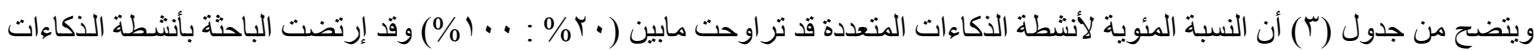

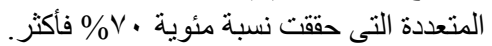

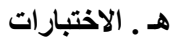

إختبار رافن للمصفوفات المتتابعة (الذكاء) مرفق (V): 
هو إختبار غير لفظى أعد هذا الإختبار "جون ر افن (J.c.Raven)"، ويستخدم هذا المقيـاس لتقدير مستوى القدرة العقلية العامـة كمـا يستخدم

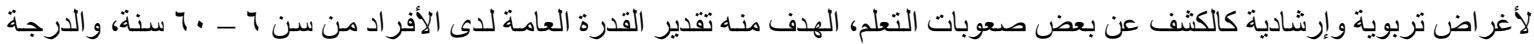

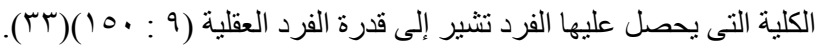

و. البرنامج التعليمي باستخدام أنثطة الذكاءات المتعددة لسباحة الصدر لطالبات الكلية ذوى صعوبات التعلم من إعداد الباحثة مرفق(9)

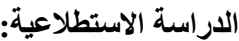

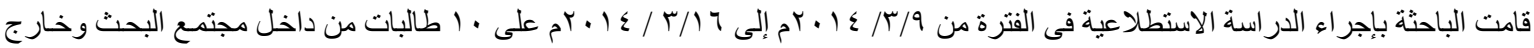

العينة الاساسية وذلك بهدف:

- - مر اءء المعاملات العلمية.

- التعرف على نقاط القوة و الضعف و الصعوبات التي قد تتعرض لها الدر اسة الأساسية.

- مدى مناسبة أنشطة الذكاءات المتعددة للطالبات.

المعاملات العلمية ( الصدق - الثبات ):

أولاً: الصدق:

استخدمت الباحثة طريقـة الاتسـاق الـاخلي لحسـاب صـدق مقيـاس الذكاءات المتعددة، كما فى جدول (ع)، استخدمت صـدق التمـايز لإختبـار

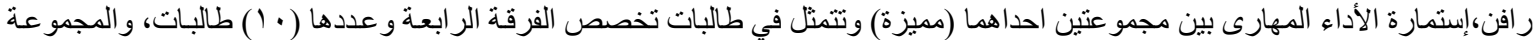

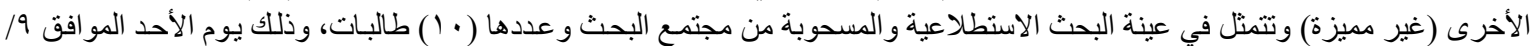

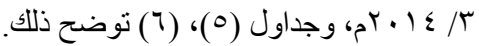

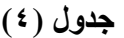

معامل الارتباط بين درجة كل عبارة والمجموع الكلى للمحور لمقياس الأكاعات المتعددة

\begin{tabular}{|c|c|c|c|c|c|c|c|c|c|}
\hline معامل الارتباط & العبارة & الأكاءع & معامل الارتباط & العبارة & الذكاء & معامل الارتباط & العبارة & \multicolumn{2}{|c|}{ نوع الأكاء } \\
\hline$\cdot, V T Y$ & 7 & \multirow{8}{*}{ 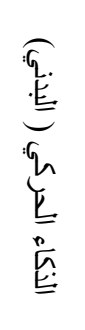 } & $\cdot, v \cdot \Lambda$ & 1 & \multirow{6}{*}{ 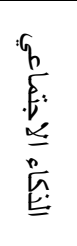 } & $\cdot, \wedge \backslash V$ & 1 & \multirow{20}{*}{ 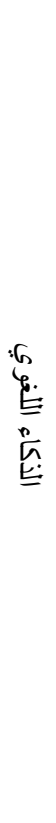 } & \multirow{20}{*}{ 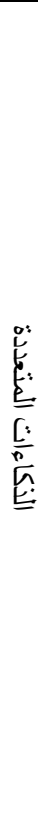 } \\
\hline$\cdot, 101$ & V & & $\cdot, V \vee V$ & $r$ & & $\cdot, \wedge \cdot \varepsilon$ & $r$ & & \\
\hline$\cdot, 101$ & $\Lambda$ & & $\cdot, \vee \wedge 1$ & $r$ & & $\cdot, 7 \wedge r$ & $r$ & & \\
\hline$\cdot, 170$ & 9 & & $\cdot, v \cdot \Lambda$ & $\varepsilon$ & & $\cdot, \wedge \backslash \mathrm{V}$ & $\varepsilon$ & & \\
\hline$\cdot, 101$ & 1. & & $\cdot, 1879$ & 0 & & $\cdot, V 9 r$ & 0 & & \\
\hline$\because V 0 \leq$ & 11 & & $\cdot, v \cdot \Lambda$ & 7 & & $\cdot, 7 \vee \wedge$ & 7 & & \\
\hline$\cdot, 107$ & Tr & & $\cdot, v \leq 7$ & 1 & \multirow{9}{*}{ 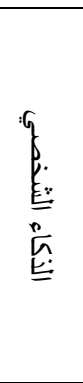 } & $\cdot, \wedge \wedge 0$ & V & & \\
\hline$\cdot, 109$ & $1 T$ & & $\cdot, \mathrm{Vr} \cdot$ & r & & $\cdot, 7 \wedge \mu$ & $\wedge$ & & \\
\hline$\cdot, V T r$ & 1 & \multirow{12}{*}{ 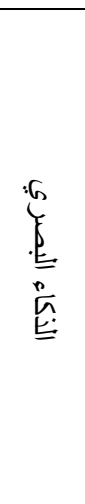 } & , , Vro & r & & $\cdot, 7 \wedge \mu$ & 9 & & \\
\hline$\cdot, V R r$ & r & & $\because, Y Y O$ & $\varepsilon$ & & $\cdot, \vee \vee 9 r$ & 1 . & & \\
\hline$\cdot, \wedge \vee T$ & $r$ & & $\cdot, \mathrm{V} \leq 1$ & 0 & & $\cdot, T \vee \wedge$ & 11 & & \\
\hline$\cdot, \wedge \wedge \vee$ & $\varepsilon$ & & $\cdot, V \leq Y$ & 7 & & $\cdot, \mathrm{V} 9 \mathrm{Y}$ & Ir & & \\
\hline$\cdot, \wedge 91$ & 0 & & $\cdot, V 0 \leq$ & $\mathrm{V}$ & & $\cdot, 7 \vee \wedge$ & $1 T$ & & \\
\hline .,7ז & 7 & & $\cdot, \times 71$ & $\wedge$ & & $\cdot, \wedge \backslash \mathrm{V}$ & $1 \leq$ & & \\
\hline$\cdot, \mathrm{V} \leq 1$ & V & & $. V \leq Y$ & 9 & & $\cdot, V 9 Y$ & 10 & & \\
\hline$\cdot, 707$ & $\Lambda$ & & $\cdot, 101$ & 1 & & $\cdot, \wedge 1 \mathrm{~V}$ & 17 & & \\
\hline$\cdot, \wedge \vee \cdot$ & 9 & & $\cdot, 107$ & r & & $\cdot, \wedge \cdot \varepsilon$ & IV & & \\
\hline$\cdot, \wedge T 1$ & 1. & & $\cdot, V T Y$ & $r$ & & $\cdot, \pi \wedge \mu$ & 11 & & \\
\hline$\cdot, \wedge 1 \cdot$ & 11 & &,, 101 & $\varepsilon$ & & $\cdot, \wedge \mid V$ & 19 & & \\
\hline$\cdot, \lambda \vee r$ & IT & & $\cdot, 101$ & 0 & & $\cdot, V 9 Y$ & $r \cdot$ & & \\
\hline
\end{tabular}

قيمة (ر) الجدولية عند (0., •) = זrاT, 


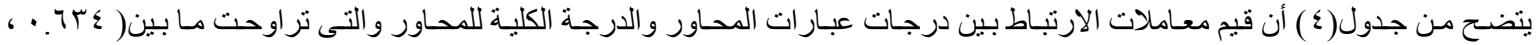

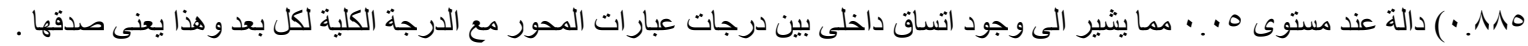

\section{جدول (•)}

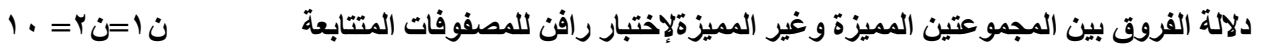

\begin{tabular}{|c|c|c|c|c|c|}
\hline \multirow{2}{*}{ 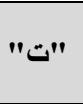 } & \multicolumn{2}{|c|}{ المجموعة غير المميزة } & \multicolumn{2}{|c|}{ المجموعة المميزة } & الإختبار \\
\hline & $\varepsilon$ & r & $\varepsilon$ & r & \\
\hline וاب. & $\varepsilon . V \leqslant$ & 07.0. & 0.99 & $7 \leq 0$. & \\
\hline
\end{tabular}

قيمة "ت" الجدوليه عند مستوى دلالة ه. . = 1 1.

يتضح من جدول (0) ورجود فروق دالـة إحصائيا بين المجموعتين المميزة وغير المميزة ولصالـح المجموعـة المميزة ممــــــل على صـدق

\section{جدول (7)}

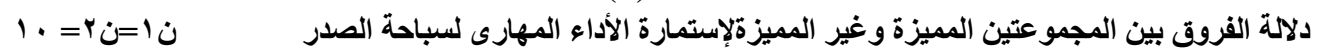

\begin{tabular}{|c|c|c|c|c|c|}
\hline \multirow{2}{*}{ قيمة " ت " } & \multicolumn{2}{|c|}{ المجموعة غير المميزة } & \multicolumn{2}{|c|}{ المجموعة المميزة } & \multirow{2}{*}{ إستمارة الأداء المهارى } \\
\hline & $\varepsilon$ & b & $\varepsilon$ & b & \\
\hline$\vee . \leqslant \wedge$ &.$\leqslant 1$ & .70 & 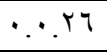 & $1 . \wedge$. & وضع الجسم \\
\hline 1r.rq &.$Y I$ & .1 &.$r o$ & $1 . v$ & حركات الرجلين \\
\hline$\vee .91$ & $\because \leqslant 1$ &. ro &. ro & $1 . v$. & حركات الذر اعين \\
\hline $1 \leqslant . V 7$ &.$r T$ & $\cdot r \cdot$ & $. Y \leq$ & 1.10 & التنفس \\
\hline $11.0 \leq$ &.$r \varepsilon$ & .10 & • & $1 . v$ & التو افق الكلى \\
\hline
\end{tabular}

قيمة "ت" الجدوليه عند مستوى دلالة ه. . = = 1.

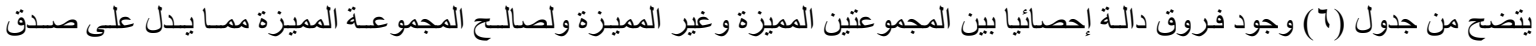

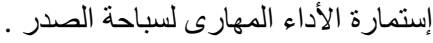

ثانياً: الثبات:

قامت الباحثة بإيجاد معامل الثبات باستخدام معامل ألفا كرونباخ لمقياس الذكاءات المتعددة، كما فى جدول (V)، بينما إستخدمت الباحثة لإختبار

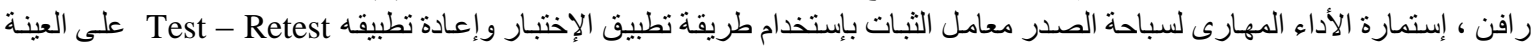

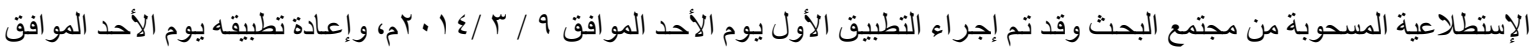
ج

\section{جدول (V)}

معامل الثبات بألفا كرونباخ لمحاور مقياس الأكاءات المتعددة

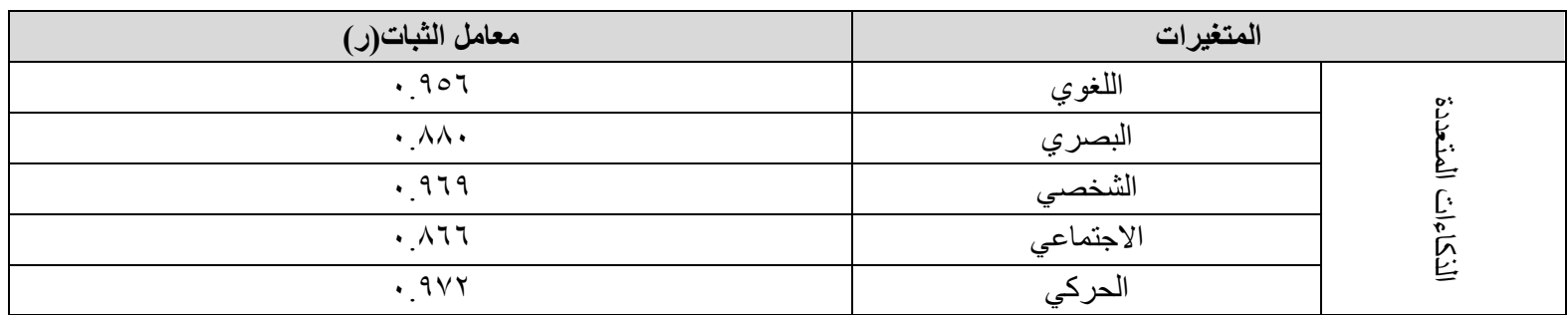

قيمة (ر) الجدولية عند (0, •) = r

يتضح من جدول (V) أن قيمة معاملات الثبات دالة إحصائيا عند مستوى (0 . • ) ويعنى بذلك ثبات المقياس المستخدم. 


\section{جدول (^)}

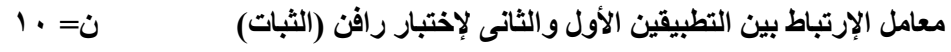

\begin{tabular}{|c|c|c|c|c|c|}
\hline \multirow{2}{*}{ قيمة "ر" } & \multicolumn{2}{|c|}{ التطبيق الثانى } & \multicolumn{2}{|c|}{ التطبيق الأول } & الإختبار \\
\hline & $\varepsilon$ & 5 & $\varepsilon$ & b & \\
\hline.$\wedge .9$ & $\varepsilon . V 7$ & ov.V. & $\varepsilon . V \leqslant$ & 07.0. & إحبّر راتن \\
\hline
\end{tabular}

قيمة "ر " الجدوليه عند مستوى دلالة ه.. =

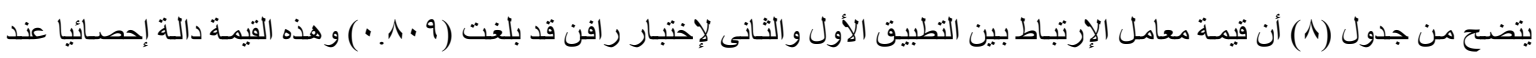

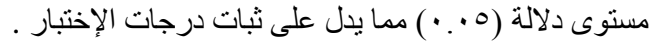

جدول (9)

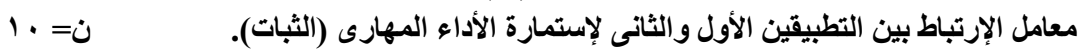

\begin{tabular}{|c|c|c|c|c|c|}
\hline \multirow{2}{*}{ قيمة "ر" } & \multicolumn{2}{|c|}{ التطبيق الثانى } & \multicolumn{2}{|c|}{ التطبيت الأول } & \multirow{2}{*}{ إستمارة الأداء المهارى } \\
\hline & $\varepsilon$ & s & $\varepsilon$ & b & \\
\hline.$\wedge r T$ &.$\leqslant 1$ & .0 &.$\leqslant 1$ & .70 & وضع الجسم \\
\hline.$V 7 \varepsilon$ & $. r \leq$ & .10 &.$Y_{1}$ & .1 & حركات الرجلين \\
\hline • & ס & $\cdot r \cdot$ & 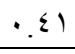 & ס מ. & حركات الذر اعين \\
\hline$\cdot . \wedge \cdot r$ &.$r \varepsilon$ & .10 &.$Y T$ & $\cdot r \cdot$ & التنفس \\
\hline$\cdot A \cdot r$ &.$r 7$ & $\because r$ & $. r \leq$ & .10 & التو افق الكلى \\
\hline
\end{tabular}

قيمة " ر " الجدوليه عند مستوى دلالة ه. .

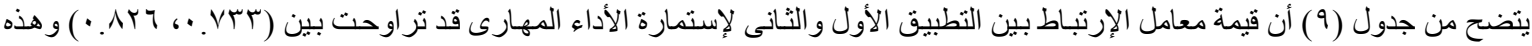

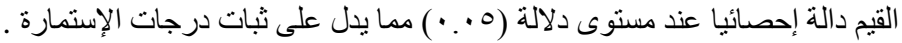

و- البرنامج التعليمي باستخدام أنشطة الأكاعات المتعددة مرفق(9)

قامت الباحثة بإعداد برنامج تعليمي لسباحة الصدر للعينة قيد البحث (طالبات الكلية ذوى صـعوبات التعلم)، بإستخدام أنشطة الذكاءات المتعددة

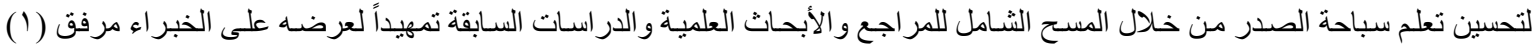

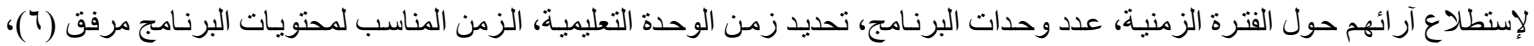

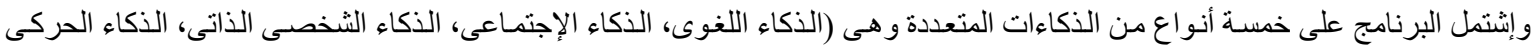

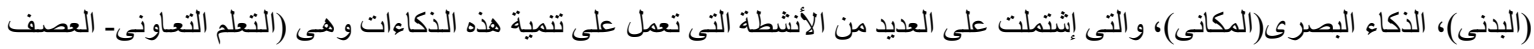

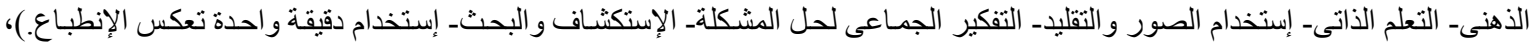
ومن خلال ذلك وضعت الباحثة البرنامج على الأسس و الخطوات التخات التالية:

| ( مدف البرنامج:

يهدف إلى تصميح وتطبيق برنامج تعليمي باستخدام أنشطة الذكاءات المتعددة على العينة قيد البحث وتأثيره على مستوى الأداء المهارى لسباحة الصدر. وينقسم الهدف العام للبرنامج إلى الأهداف الآتية: أولاً: أهداف معرفية وتتمثل فى:

تزويد الطالبات بمعلومات ومعارف عن سباحة الصدر.

اكتساب الطالبات بعض مهار ات التفكير.

اكتساب الطالبات القدرة على تقويم أقر انهم.

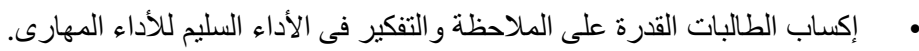

ثانياً: أهداف مهارية وتتمثل فى : 
تتمية التوافق الحركي بين أجزاء الجسم المختلفة أثناء الأداء. تنمية القدرة لاى الطالبات على وصف الأداء الصحيح لسباحة الصدر. تتمية القدرة لدى الطالبات على التمييز بين اوجه التشابه والاختلاف. تتمية مستوى الأداء المهارى لسباحة الصدر. ثالثاً: أهداف وجدانية وتتمثل فى: اكتساب الطالبة الثقة و الاعتماد على النفس. إكساب الطالبات القيم والعادات و الاتجاهات الايجابية السليمة. بناء وتحقيق التكامل فى شخصية الطالبات. اكتساب الطالبة القدرة على تركيز الانتباه أثناء الأداء.

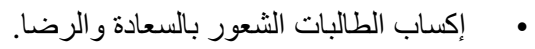

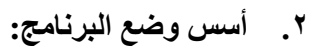
• أن يحقق الهدف الذى وضع من أجله.

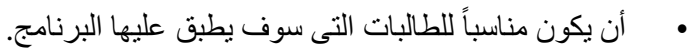

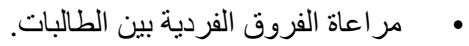
• مرونة البرنامج وقبوله للتعديل.

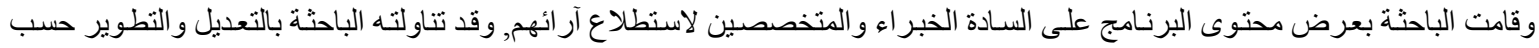
التوجيهات، وتم عرض البرنامج فى صورته النهائية على السادة الخبر اء مرة أخرى حتى تم الاتفاق على صلاحيته من حيث المحتوى أنى وطريقة التطبيق.

الإطار العام لتنفيذ البرنامج:

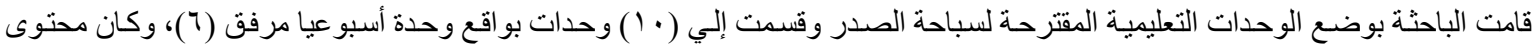

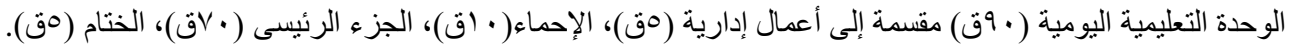
أجز اء الوحدة التعليمية اليومية:

$$
\text { أو لاً: الإحماء (·) : (ق) }
$$

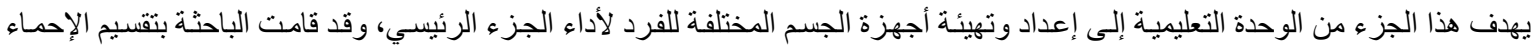

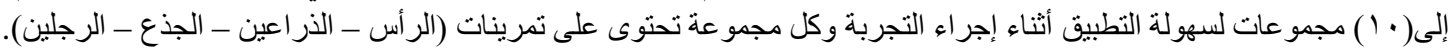

$$
\text { ثانياً: الجزء الرئيسى ( لتعليم سباحة الصدر ) ( • ق)): }
$$

تضمنت هذه الفترة الأهداف المعرفية و المهارية والوجدانية، فقد نوعت الباحثة فى استخدم أنشطة الذكاءات المتعددة التي تم الاتفاق عليها من

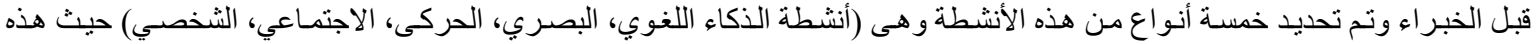

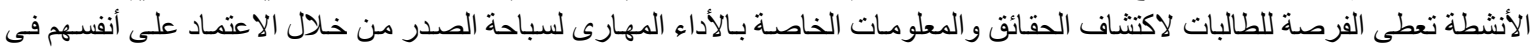

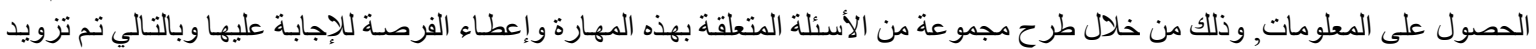

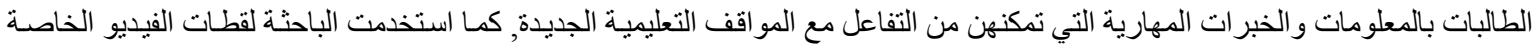

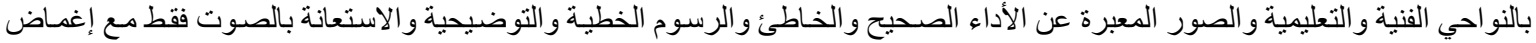

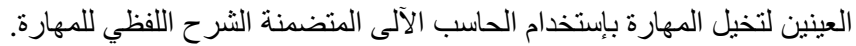
كما أعطت الباحثة للطالبة الو اجبات التالية-: تصوير الزميلة أثناء التمرين وتحليل الأداء وتوضيح الأخطاء. رسم المر احل الفنية لسباحة الصدر مع توضيح التسلسل الحركى للأداء. 
عمل البوم صور للتسلسل الحركى لسباحة الصدر .

تدوين الطالبة للتدريبات التى تم إستخدامها داخل المحاضرة.

• عمل ورقة علمية عن التدريبات التعليمية الخاصة بسباحة الصدر من خلال شبكة المعلومات و المر اجع العلمية المتخصصة.

• تصميم لوحات توضيحية تثمل الخطوات التعليمية والفنية لسباحة الصدر.

ثالثاً: جزء التهرئة (الختام) (هق):

يو جد فى نهاية كل وحدة تعليمية يومية بهذف تنظيم عملية التنفس التي تؤدى إلى انتظام معدل دقات القلب, وعودة أجهزة الجسم المختلفة لحالتها

الطبيعية.

الخطوات التفيذية للبحث

أولاً: القياس القبلي

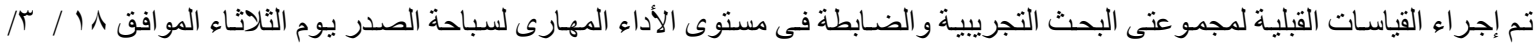

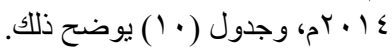

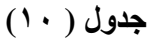

دلالة الفروق بين مجموعتى البحث التجريبية والضابطة فى مستوى الأداء المهارى لسباحة الصدر لطالبات الكلية ذوى صعوبات التعلم

$r \cdot=r \dot{u}=10$

(التكافؤ)

\begin{tabular}{|c|c|c|c|c|c|c|c|}
\hline \multirow{2}{*}{ قيمة (ت) } & \multirow{2}{*}{ م ف } & \multicolumn{2}{|c|}{ المجموعة الضابطة } & \multicolumn{2}{|c|}{ المجموعة التجريبية } & \multirow{2}{*}{ وحدة القياس } & \multirow{2}{*}{ المتغيرات } \\
\hline & & $\varepsilon$ & 5 & $\varepsilon$ & 5 & & \\
\hline $1 . \varepsilon$ & .11 &.$\Gamma \Lambda$ & $\because 7$ & $\because \leqslant 1$ & 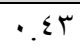 & الدرجة & وضع الجسم \\
\hline$\because V Y$ & $\because .0$ & $\cdot r \leqslant$ & .10 & $\cdot r$ & $\because 1$ & الدرجة & حركات الرجلين \\
\hline . & $\because \cdot r$ & $\cdot r \leqslant$ & .11 & $\cdot r \varepsilon$ & .10 & الدرجة & حركات الذراعين \\
\hline.$\vee \wedge$ & $\because .0$ & .11 & $\because \wedge$ & $\cdot r r$ & .14 & الدرجة & التنفس \\
\hline $1.1 \pi$ & $\because \cdot V$ &.$r \varepsilon$ & .10 & .11 & $\because \cdot \lambda$ & الدرجة & التوافق الكلى \\
\hline
\end{tabular}

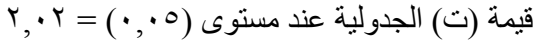

يتضح من جدول ( • (1) عدم وجود فروق دالة إحصائياً بين القياسات القبلية لمجمو عتى البحث التجريبية و الضـابطة فى مستوى الأداء المهارى،

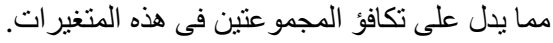

\section{ثانيا: تطبيق تجربة البحث الأساسية:}

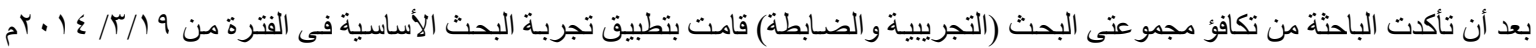

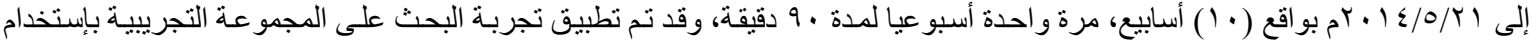

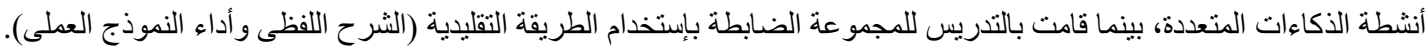

ثالثاً: القياس البعدي

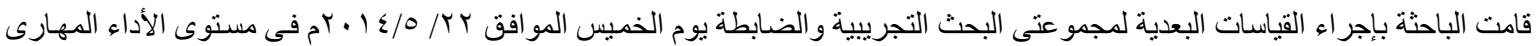
لسباحة الصدر.

رابعاً: المعالجات الإحصائية

استخدمت الباحثة الأساليب الإحصائية التالية لمعالجة بيانات البحث باستخدام برنامج SPSS

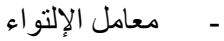

-

- اختبار (ت) لمجمو عتين متساويتين - الوسيط - - - الانحر اف المعيارى 
عرض النتائج ومناقشتها :

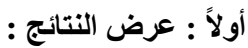

جدول (11)

دلالة الفروق بين متوسطى القياسين القبلى والبعدى للمجموعه التجريبيه فى مستوى الأداء المهارى لطالبات الكلية ذوى صعوبات التعلم ن

\begin{tabular}{|c|c|c|c|c|c|c|c|}
\hline \multirow{2}{*}{$ت$} & \multirow{2}{*}{ ع ف } & \multirow{2}{*}{ م ف } & \multicolumn{2}{|c|}{ القياس البعدى } & \multicolumn{2}{|c|}{ القياس القبلى } & \multirow{2}{*}{ المتغيرات } \\
\hline & & & $\varepsilon$ & r & $\varepsilon$ & s & \\
\hline A. $\leqslant 7$ &. $.0 \mathrm{~V}$ & 1.1 & $\because \leqslant 9$ & 1.0. &..$\leqslant 1$ &.$\leqslant T$ & وضع الجسم \\
\hline $10 . r$ &.$r \Lambda$ & $1 . Y \wedge$ &.$\leqslant r$ & $1 . r \wedge$ &..$\leqslant V$ & .1 & حركات الرجلين \\
\hline 11.7. &..$\Sigma V$ & $1 . r \pi$ &.$\leqslant 7$ & $1 . r \lambda$ & $\cdot r \varepsilon$ &. .10 & حركات الذراعين \\
\hline $1 \cdot r \varepsilon$ & 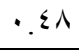 & 1.1. &.$\leqslant V$ & $1 . r r$ & $\cdot . Y Y$ &. .14 & التنفس \\
\hline $1 \cdot . \leqslant T$ &. Or & $1 . r T$ & $.0 \mathrm{~V}$ & $1 . r$ & .11 & $\because \cdot 1$ & التوافق الكلى \\
\hline
\end{tabular}

قيمة " ت " الجدوليه عند مستوى دلالة ه . .

يتضح من جدول (1) (1) وجود فروق دالة إحصـائيا بين متوسطى القياسين القبلى و البعدى للمجموعة التجريبيه فى مستوى الأداء المهارى لسباحة الصدر لصالح منوسط القياس البعدى.

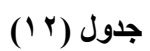

دلالة الفروق بين متوسطى القياسين القبلى والبعدى للمجموعه الضابطة فى مستوى الأداء المهارى لطالبات الكلية ذوى صعوبات التعلم r.

\begin{tabular}{|c|c|c|c|c|c|c|c|}
\hline \multirow{2}{*}{$ت$} & \multirow{2}{*}{ ع ف } & \multirow{2}{*}{ م ف } & \multicolumn{2}{|c|}{ القياس البعدى } & \multicolumn{2}{|c|}{ القياس القبلى } & \multirow{2}{*}{ المتغيرات } \\
\hline & & & $\varepsilon$ & P & $\varepsilon$ & 5 & \\
\hline$\cdot .^{\prime \prime}$ & 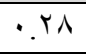 & $\because .0$ &.$\varepsilon$ & .70 & $\cdot \mathrm{r} \Lambda$ & .7 & وضع الجسم \\
\hline I.rV & $\cdot r \leqslant$ & $\because \cdot 1$ & $\cdot r \varepsilon$ & 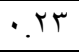 & $\cdot r \leqslant$ & .10 & حركات الرجلين \\
\hline $1 . r v$ & $\cdot r \varepsilon$ & $\because \cdot 1$ & $\cdot r$. & $\therefore r_{0}$ & $\cdot r \leqslant$ &. .11 & حركات الذراعين \\
\hline 1.21 & $\cdot r_{T}$ & .1 &.$Y \xi$ & .11 & .11 & $\because \cdot 1$ & التنفس \\
\hline$\cdot .11$ &.$T_{\Lambda}$ & $\because .0$ &.$r$. & $\cdot r^{\prime}$ & $\cdot r \leqslant$ & .10 & التوافق الكلى \\
\hline
\end{tabular}

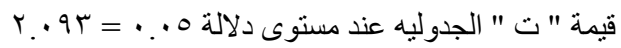

يتضح من جدول (r I ) وجود فروق غير دالة إحصائيا بين متوسطى القياسين القبلى و البعدى للمجموعة الضـابطة فى مستوى الأداء المهارى لسباحة الصدر لصالح منوسط القياس البعدى.

جدول ( ب ا

دلالة الفروق بين القياسين البعديين لمجموعتى البحث التجريبية والضابطة فى مستوى الأداء المهارى لطالبات الكلية ذوى صعوبات التعلم ن

\begin{tabular}{|c|c|c|c|c|c|c|}
\hline \multirow{2}{*}{ "ت " " } & \multirow{2}{*}{ الفرق بين المتوسطين } & \multicolumn{2}{|c|}{ المجموعة الضابطة } & \multicolumn{2}{|c|}{ المجموعة التجريبية } & \multirow{2}{*}{ المتغيرات } \\
\hline & & $\varepsilon$ & 5 & $\varepsilon$ & p & \\
\hline $7 . r$ & .10 & $\because \varepsilon$ & .70 &.$\leqslant 9$ & 1.0. & وضع الجسم \\
\hline 9.81 & 1.10 & $\cdot r \xi$ & . & $\cdot \varepsilon r$ & $1 . r \lambda$ & حركات الرجلين \\
\hline 9.19 & $1.1 \pi$ & $\cdot r \cdot$ & ro & $\cdot \leq 7$ & $1 . r \wedge$ & حركات الذراعين \\
\hline ^.^r & 1.0 & 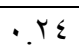 & .11 &.$\leqslant V$ & $1 . r \mu$ & التنفس \\
\hline V.Tr & 1.1. & $\cdot r \cdot$ &.$r$. & $.0 \mathrm{~V}$ & 1.r. & التوافق الكلى \\
\hline
\end{tabular}

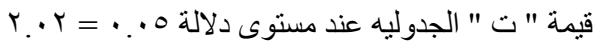


يتضح من جدول ( آ ) و وجود فروق دالة إحصائيا بين القياسين البعديين لمجمو عتى البحث التجريييه و الضـابطه فى مستوى الأداء المهارى لسباحة الصدر لصالح منوسط القياس البعدى للمجمو عة التجريبية.

ثانياً: مناقثة النتائج يتضح من جدول (1) (1) وجود فروق دالة إحصائياً بين القياسين القبلي و البعدي للمجمو عة التجريبية فى مستوى الأداء المهارى لسباحة الصدر لصالح القياس البعدي.

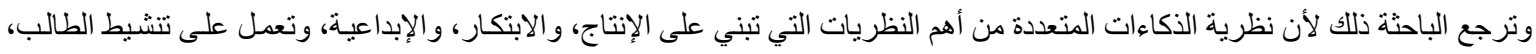

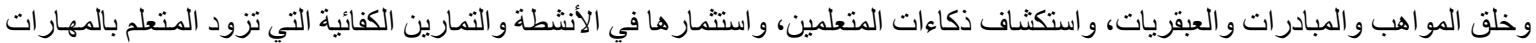

و القدر ات لحل المشاكل، و إيجاد مشكلات أخرى وحلها.

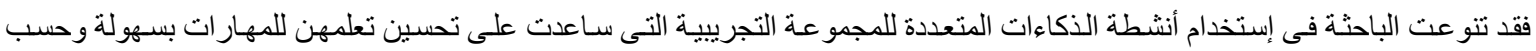

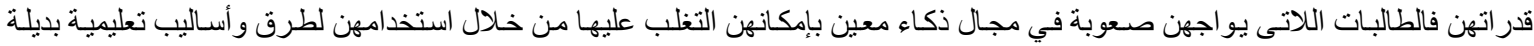

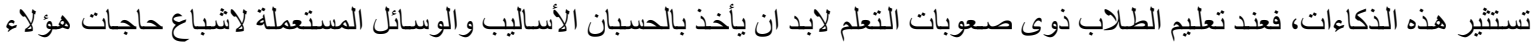
الطلاب الأساسية.

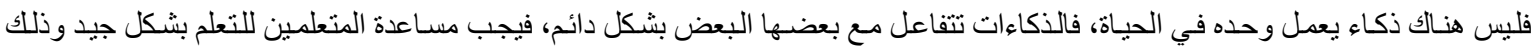
بتوظيف الذكاءات الأكثر تفوقاوتقوية الذكاءات التي هي في حاجة إلى ذللك، في الوقت نفساء.

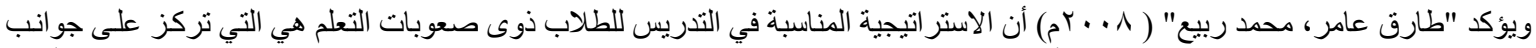

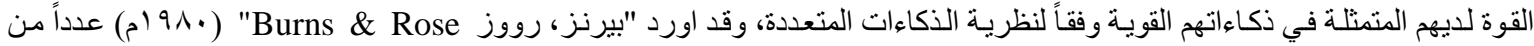

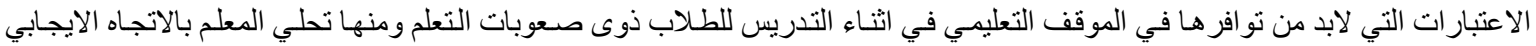

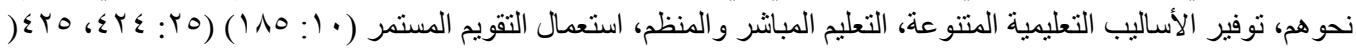

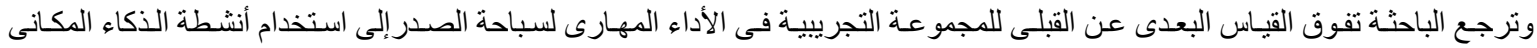

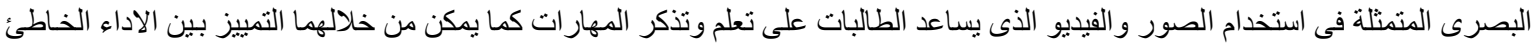

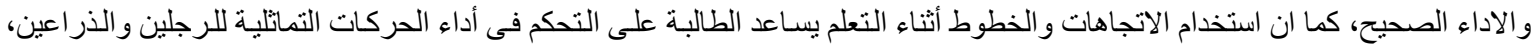

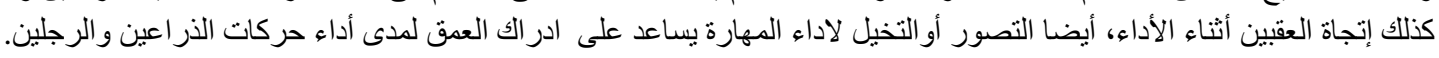

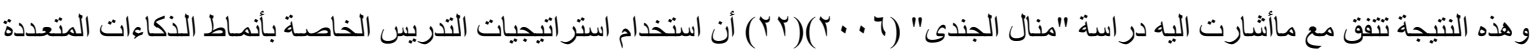

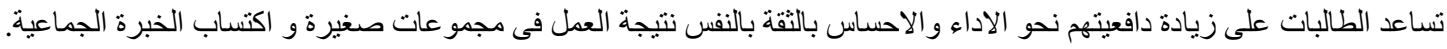

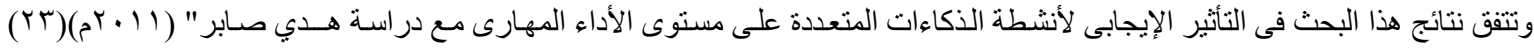

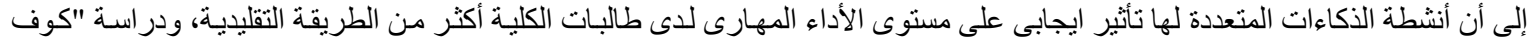

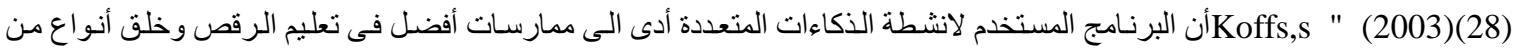

الرقص تتجاوز التقنية البسيطة.

وبذلك يتحقق الفرض الأول و الذى ينص على: "توجد فروق دالة إحصائياً بين القياسين القبلي و البعدي للمجموعة التجريبية على مستوى الأداء المهارى لسباحة الصدر لطالبات الكلية ذوى صعوبات التعلم لصالح القياس البعدي."

بينما يتضح من جدول (r ( ) وجود فروق غير دالة إحصائياً بين منوسطي القياسين القبلي و البعدي للى المجموعة الضـابطة في مستوى الأداء المهارى لسباحة الصدر لصالح القياس البعدي.

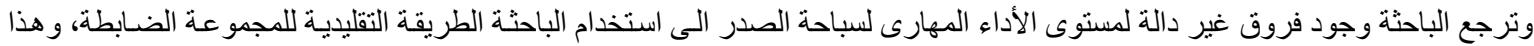

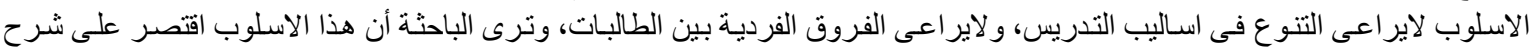
المهارة و اعطاء نموذج و التكر ار فقط دون التعرض لاع لاع نشاط يثرى الافكار ويعمل على جذب الانتباه ويزيد من دافعيتهم نحو الانجاز. فكان تعلم المجمو عـة الضـابطة بإستخدام الثرح اللفظى وأداء النموذج العملى يتم بشكل بطىء لطالبات الكلية ذوى صعوبات التعلم لسباحة 


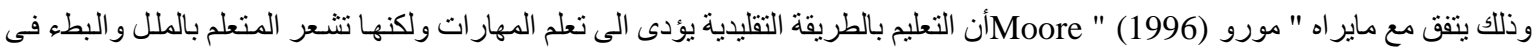

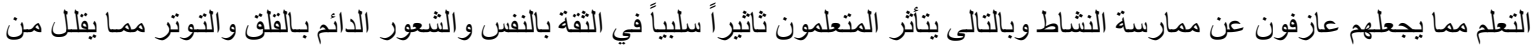

دافعينهم نحو الانجاز (r) (ب)

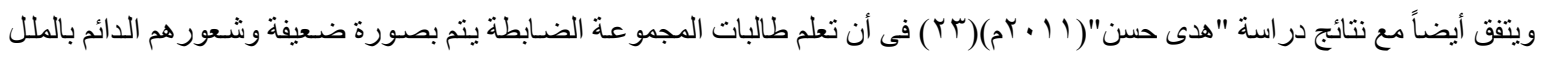
و والقق و التوتر. وبذلك يتحقق الفرض الثانى و الذى ينص على: "توجد فروق غير دالة إحصائياً بين القياسين القبلي و البعدي للمجموعة الضـابطة على مستوى الأداء المهارى لسباحة الصدر لطالبات الكلية

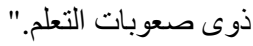

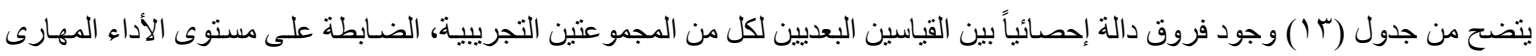
لسباحة الصدر لطالبات الكلية ذوى صعودات فروف دالتعلم لصالح القياس البعدي للمجموعة التجريبية.

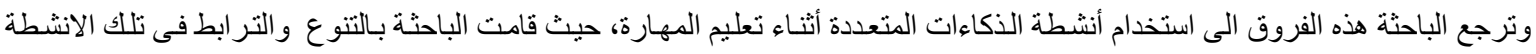

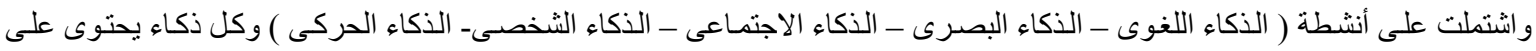

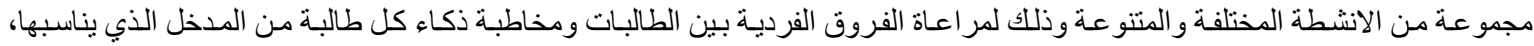

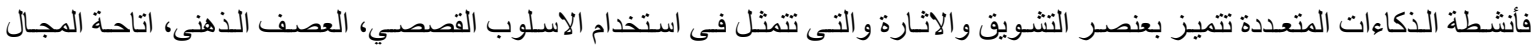

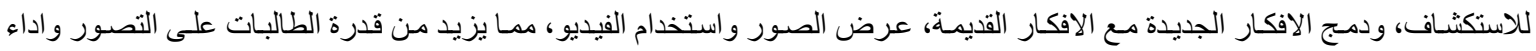

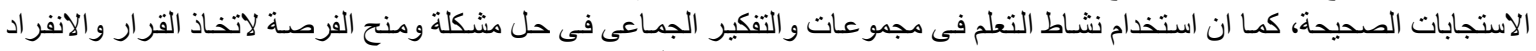

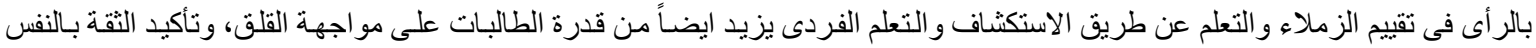

لايهن.

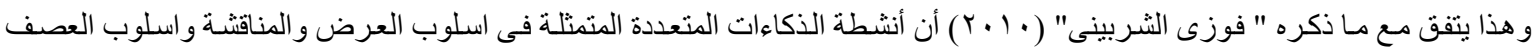

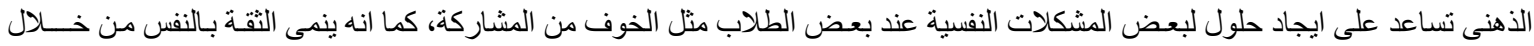

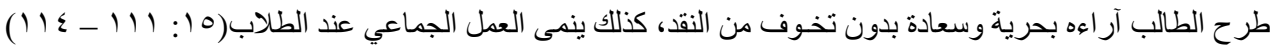

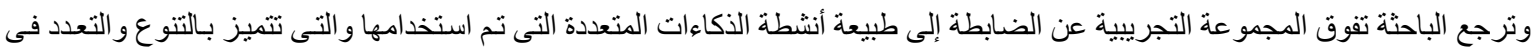

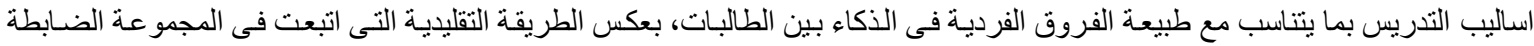
و التى تعتمد على الثرح و أداء النموذج و التكر ار فتصبح الطالبة مستمعة ومقلدة.

و هذا يتفق مع ما أثنارت اليه "عفاف حسن"( •99 (19) إلي أن كل أسلوب له دور معين في نماء الطالب (المتعلم) من الناحية البدنية و الاجتماعية

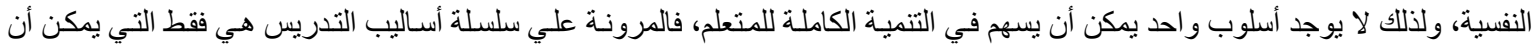

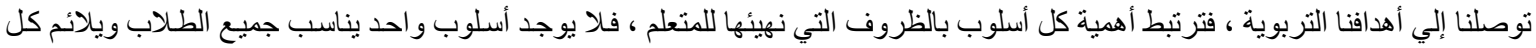

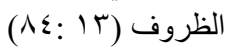

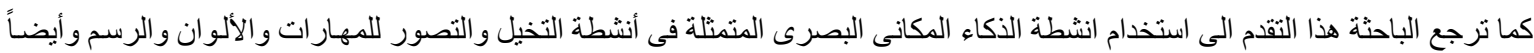

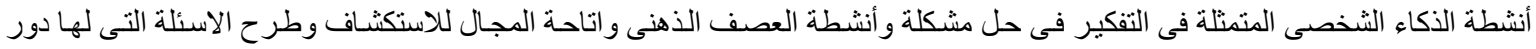

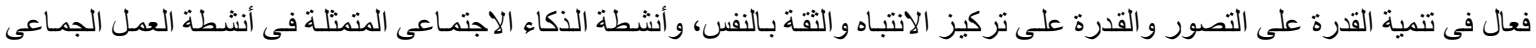

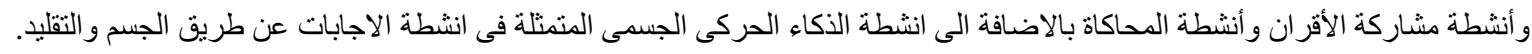

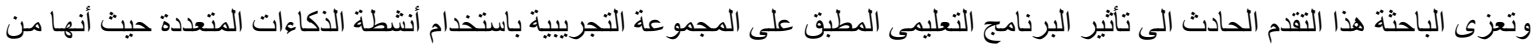

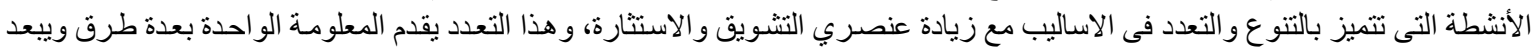

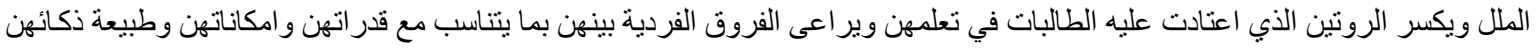
مما جعل الطالبات أكثر قبو لا على التعلم وأكثر ايجابية فى العملية التعليمية وبالتالى تقدم الأداء.

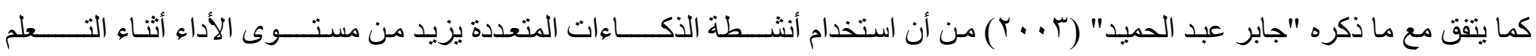

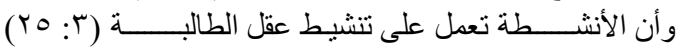

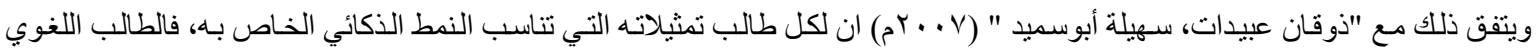

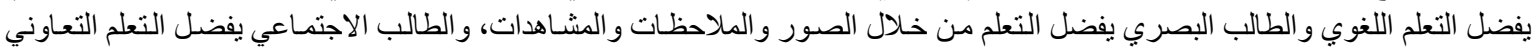

و هكذا (T : : (T). 
وفيما يخص المجمو عة الضابطة فكانت درجاتهم اقل من المجموعة التجريبية فى الأداء المهارى، وترجع الباحثة ذلك الى استخدام الطريقة

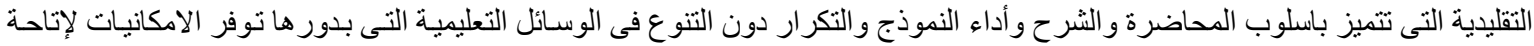
الفرص التعليمية المناسبة للطالبات، كما أنها لاتر اعى الفروق الترائ الفردية بين الطالبات و لا طبيعة ذكائهن.

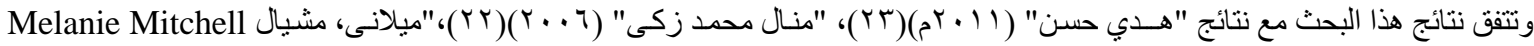

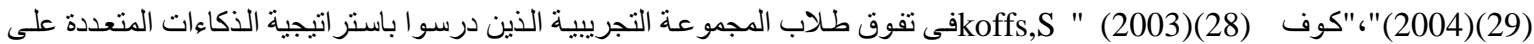
طلاب المجمو عة الضابطة الذين درسو البالطريقة التقليدية.

$$
\text { وبذلك يتحقق الفرض الثالث الذي ينص على }
$$

"توجد فروق دالة إحصائياً بين القياسين البعديين لكل من المجمو عتين التجريبية، الضابطة على مستوى الأداء المهارى لسباحة الصدر لطالبات

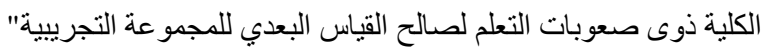

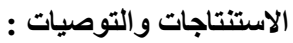

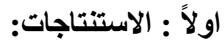

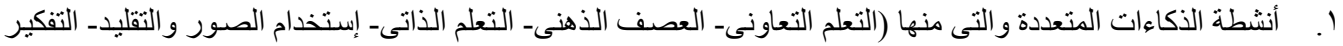

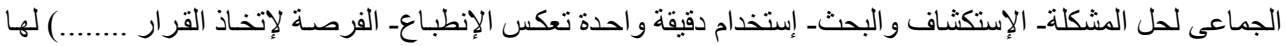

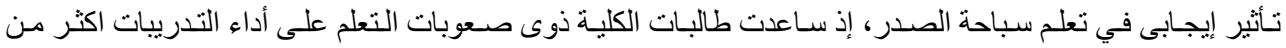

الطريقة الاعتيادية.

r. أنثطة الذكاءات المتعددة زادت من اكتسـاب الطالبات للتدرييات لسباحة الصدر لطالبات الكلبة ذوى صعوبات التعلم

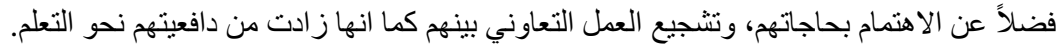

تعلم المجمو عة الضابطة بإستخدام (الثرح اللفظى و أداء النموذج العملى) يتم بشكل بطىء لطالبات الكلية ذوى صعوبات

التعلم لسباحة الصدر.

ع. تفوق طلاب المجموعة التجريبية الذين درسوا باستر اتيجية الذكاءات المتعددة على طلاب المجمو عة الضـابطة الذين

درسو ا بالطريقة التقليدية.

•. أنثطة الذكاء المكانى البصرى المتمثل فى إستخدام الصور و الفيديو سـاعد الطالبات على تعلم وتذكر المهار ات لسباحة

الصدر.

ثانياً: التوصيات:

- إعتبار الذكاءات المتعددة أساس ومدخل هام فى تعليم السباحة للطالبات ذوى صعوبات التعلم بالكلية.

- إعداد إختبار ات مقننة بإمكانها الكثف و التحديد و التشخيص و التقويم.

الإلمام بأهمية و أساليب الذكاءات المتعددة وتطبيقاتها المختلفة بالنسبة للطلاب و المعلمين.

- الربط بين النظرية و التطبيق فى تعليم السباحة.

- إجر اء دراسة تقارن أثر استر اتيجية الذكاءات المتعددة باستر اتيجيات تدريسية اخرى.

- بناء مقياس لإكتشاف الطلبة ذوى صعوبات التعلم فى السباحة مهارياً ومعرفياً.

ـ اعتماد النظرة الثمولية متعددة الابعاد لمجالات الذكاء المختلفة لدى المتعلمين و عدم الحكم عليهم اعتماداً على ذكاء واحد

( الذكاء المنطقي ) كما يسود في معظم المؤسسات التعليمية.

- اعتماد المعلم على استر اتيجيات و أساليب تدريس مناسبة لذوي صعوبات التعلم، والاهتمـام بجو انب القوة لديهم في تعلم

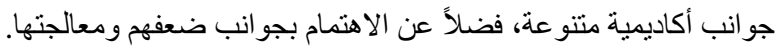

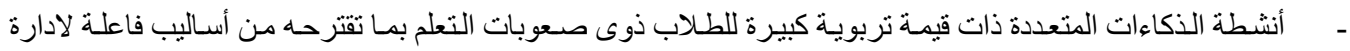

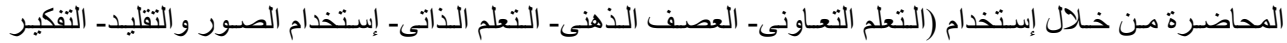

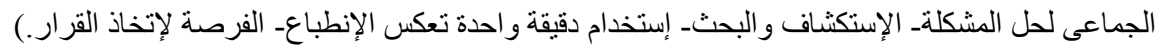




\section{أولاً :المراجع العربية:}

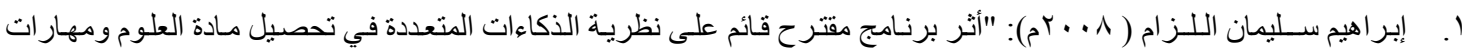

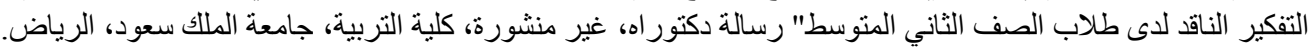

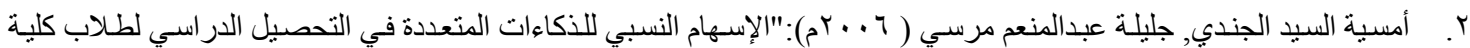

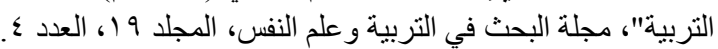

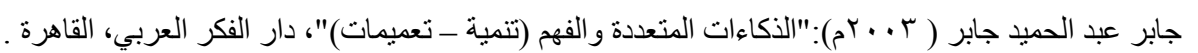

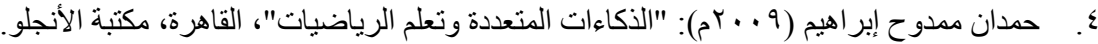

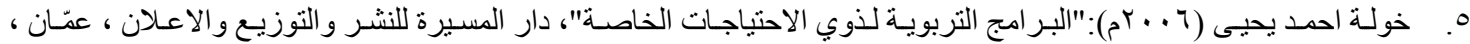
الاردن.

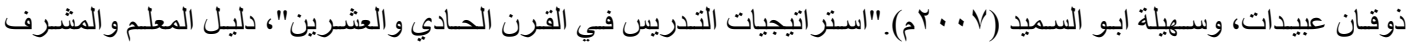
التزبوي، دار الفكر، عمان.

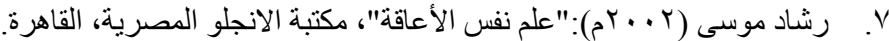

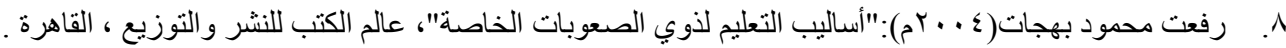

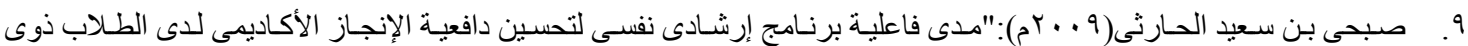

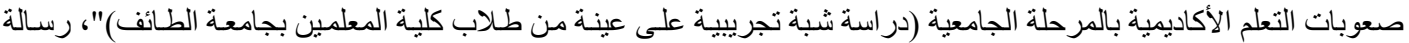
دكتور اة، كلية التربية، جامعة أم القرى".

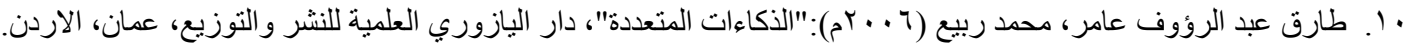

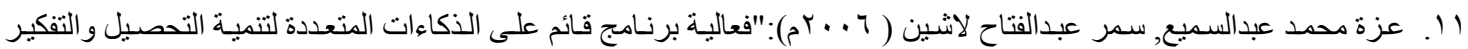

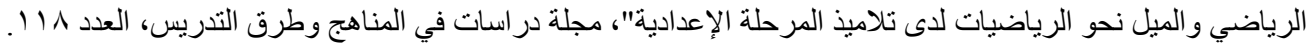

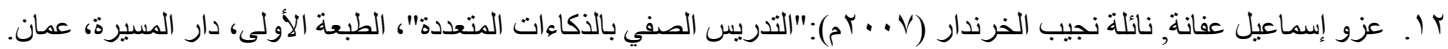

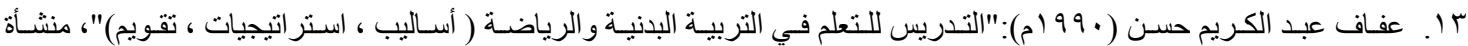
المعارف، الإسكندرية.

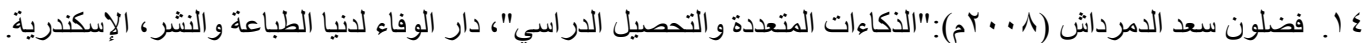

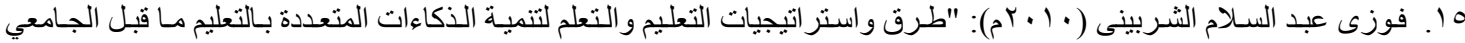

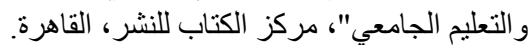
17 1. كوثر كوجك (999 (1)):"إتجاهات حديثة فى المناهج وطرق التنريس"، القاهرة، عالم الكتب.

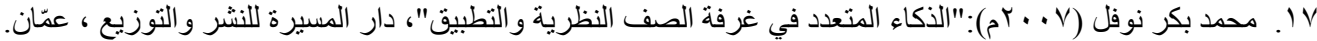

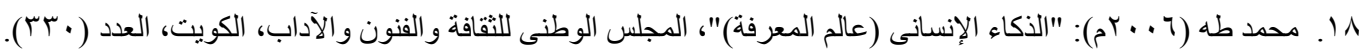

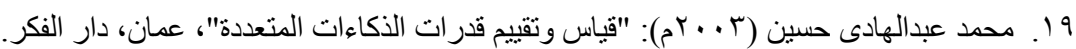
• •.. محمد على القط (999 (99):"المبادئ العلمية للسباحة"، دار القبس للطباعة.

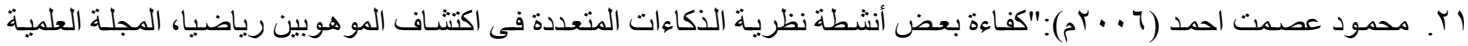
لعلوم التربية البدنية والرياضة"، كلية التربية الرياضية ،جامعة المنصورة، المجلد (V).

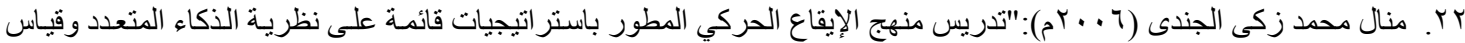

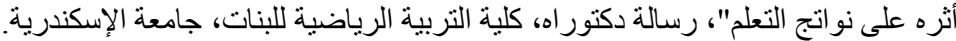

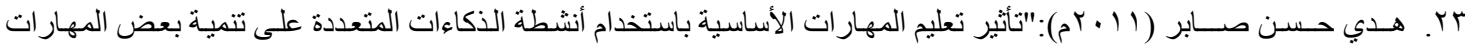

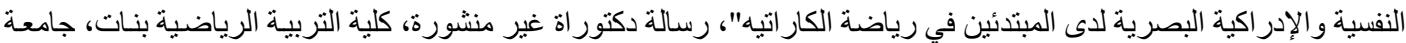
الزقازيق. ع ז. وفيقة مصطفى سالم (997 (1)): "الرياضات المائية"،منشأة المعارف،الإسكندرية. 


\section{ثانياً :المراجع الأجنبية:}

25. Burns , P.C. and B. D. Rose (1989): "Teaching in Todays Elementary schools", Houghton Mifflin company, second Edition , Boston , 1980 , p. $424-425$.

26. Gardner, Howard (1991). "Intelligence Reframed, Multiple Intelligences for the 21 st Century", New York: Basic books

27. Gardner, H(2005): "Las cincos ments del future: Un ensayo educativo. Paidos Asterico.

28. Koff,s- R .(2003):"why the multiple intelligen?",Basic, Journal- of Dance - Education, andvoer.

29. Melanie Mitchell , Michael Kernodle.(2004):" Using Multiple Intelligences to Teach Tennis", Journal of Physical Education, Recreation and Dance, Issue: October. Available:http://www.questia.com/googleScholar.qst?docId=5007704647

30. Moore, R. E. (1996): "Effects of the use of Two diffrent Teaching styles on motor skill acquisition of fifth-grade stadents".Thesis (Ed. D.) East Texas State University.

31. Wang Jia Li (2009): "Cultivation of student's teaching and curriculum development capacities via the aerobics course from the perspective of the theory of multi-area intelligence": Journal of Physical Education Vol,16 No. 11.

\section{ثالثاً : شبكة المعلومات الدولية :}

32. http://www.fifee.com 15/3/ 2014

33. http://www.edutest.0fees.net/rspm/Untitled_1.htm 17/3/2014

34. http://www.infed.org/thinkers/gardner.html 17/ 3/ 2014 


\section{الملخص باللغة العربيـة}

تأثير إستخدام أنشطة الذكاءات المتعددة على مستوى الأداء المهارى لسباحة الصدر لطالبـات الكليـة ذوى صعوبات التعلم. مايسة محمد عفيفى السيد قسم الرياضات المائية والمنازلات ـ كلية التربية الرياضية بنات - جامعة الزقازيق ـ جمهورية مصر العربية.

يهدف البحث إلي التعرف على تأثير برنامج تعليمى بإستخدام أنشطة الذكاءات المتعددة على مستوى الأداء المهارى لسباحة الصدر لطالبات

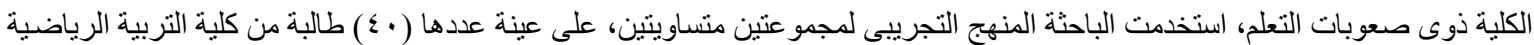
بنات بجامعة الزقازيق .

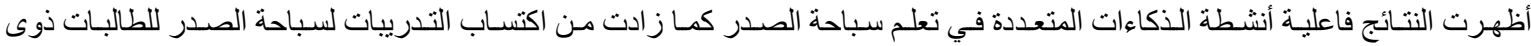
صعوبات التعلم فضلاً عن الاهتمام بحاجاتهم، وتثجيع العمل التعاوني بينهم كما انها زادت من دافعيتهم نحو التعلم.

فقد أوصت الباحثة بإنشاء وحدة لتشخيص و علاج صعوبات التعلم لتؤدى دورا فعالا ومؤثراً فى مساعدة هؤ لاء الطلاب ور عايتهم، الإلمسام

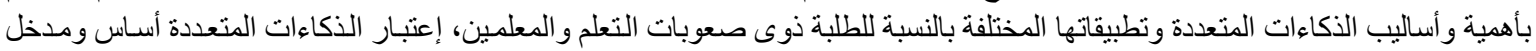
هام فى تعليم السباحة. 
The effectiveness of using multiple intelligenees activities on the skill level in breaststroke for faculty students with learning disabilities.

\section{Maysa Mohamed Afifi El-Sayed}

The research aims to identify the impact of using an educational program to learn about the effectiveness of using multiple intelligences activities on the skill level in breaststroke for students with learning disabilities, the researcher used the experimental method to two equal groups, on a sample of 40 students from the Faculty of Physical Education for girls at Zagazig University.

The results showed the effectiveness of the multiple intelligences activities in learning breaststroke also increased from the acquisition of the exercises to Breaststroke for students with learning disabilities as well as attention to their needs, and encourage collaborative work among them as it had increased the motivation toward learning.

Researcher recommended the establishment of a unit diagnosis and treatment of learning disabilities to play an active and influential role in helping these students and their care, the importance of knowledge and methods of multiple intelligences and various applications for students with learning disabilities and teachers, consideration of multiple intelligences and important entrance in swimming instruction basis. 
